Article

\title{
Multidimensional Approaches to Examining Digital Literacies in the Contemporary Global Society
}

\author{
Kewman M. Lee ${ }^{1, *}$, Sohee Park ${ }^{2}$, Bong Gee Jang ${ }^{3}$, and Byeong-Young Cho ${ }^{4,5}$ \\ ${ }^{1}$ Reading, Foundations and Technology, Missouri State University, Springfield, MO 85687, USA; \\ E-Mail: kewmanlee@missouristate.edu \\ 2 Chadwick School, Palos Verdes Peninsula, CA 90274, USA; E-Mail: ipadsohee@gmail.com \\ ${ }^{3}$ Reading and Language Arts, Syracuse University, Syracuse, NY 13244, USA; E-Mail: bojang@syr.edu \\ ${ }^{4}$ School of Education, University of Pittsburgh, Pittsburgh, PA 15213, USA; E-Mail: choby@pitt.edu \\ ${ }^{5}$ Learning Research and Development Center, University of Pittsburgh, Pittsburgh, PA 15213, USA; E-Mail: choby@pitt.edu \\ * Corresponding author
}

Submitted: 22 January 2019 | Accepted: 26 April 2019 | Published: 11 June 2019

\begin{abstract}
Literacy scholars have offered compelling theories about and methods for understanding the digital literacy practices of youth. However, little work has explored the possibility of an approach that would demonstrate how different perspectives on literacies might intersect and interconnect in order to better describe the multifaceted nature of youth digital literacies. In this conceptual article, we adopt the idea of theoretical triangulation in interpretive inquiry and explore how multiple perspectives can jointly contribute to constructing a nuanced description of young people's literacies in today's digitally mediated global world. For this purpose, we first suggest a triangulation framework that integrates sociocultural, affective, and cognitive perspectives on digital literacies, focusing on recent developments in these perspectives. We then use an example of discourse data from a globally connected online affinity space and demonstrate how our multidimensional framework can lead to a complex analysis and interpretation of the data. In particular, we describe the substance of one specific case of youth digital literacies from each of the three perspectives on literacy, which in turn converge to provide a complex account of such literacy practices. In conclusion, we discuss the promise and limitations of our integrative approach to studying the digital literacy practices of youth.
\end{abstract}

\section{Keywords}

Border-Crossing Discourse; digital literacies; epistemic cognition; self-determination theory; theoretical triangulation; youth digital literacies

\section{Issue}

This article is part of the issue "Critical Perspectives on Digital Literacies: Creating a Path Forward", edited by Hiller A. Spires (North Carolina State University, USA).

(C) 2019 by the authors; licensee Cogitatio (Lisbon, Portugal). This article is licensed under a Creative Commons Attribution 4.0 International License (CC BY).

\section{Introduction}

Literacy scholars have offered compelling theories and methodologies for understanding youths' digital literacy practices (e.g., Alvermann, 2010; Baker, 2010; Coiro, Knobel, Lankshear, \& Leu, 2008). However, the goals and purposes, methodological considerations, and strengths and limitations of literacy studies vary according to the views that scholars take of what literacy means. For ex- ample, if one sees literacies as practices that are socially situated (Gee, 1990; Street, 1995), then one may pay attention to how the members of a certain social group represent, negotiate, and formulate their stances and identities to meet their goals and interests (e.g., Latinx social groups in Jiménez, 2000, and Moll, Amanti, Neff, \& Gonzalez, 1992; urban social groups in Moje \& Lewis, 2007, and Morrell, 2004; transnational communities in Jiménez, Smith, \& Teague, 2009, and Skerrett, 2015). On 
the other hand, if others find the meaning of literacy in the way that an individual mind works, they may focus on the intricate cognitive processes of the individual engaged in reading, writing, thinking, and reasoning in response to texts of different contents and forms (e.g., the functions of reader schema in Anderson \& Pearson, 1984; the process of mental model-building in Kintsch, 1988; writers' cognitive acts in response to rhetorical contexts in Flower \& Hayes, 1981).

Similarly, perspectives matter in literacies inquiries situated in the twenty-first-century digital world. Researchers who take sociocultural views of digital literacies interpret what can be afforded and constrained in a variety of online social groups and how digital communities are initiated, formed, and developed toward creating a space for the engagement and participation of youths (e.g., digital media and popular culture in Alvermann, 2010; video gaming communities in Gee \& Hayes, 2010; globally connected online literacy practices in Hull, Stornaiuolo, \& Sahni, 2010, and Hull, Stornaiuolo, \& Sterponi, 2013; multilingual literacies in digitally mediated transnational online contexts in Lam \& RosarioRamos, 2009). On the other hand, other scholars whose perspectives emphasize cognitive aspects of individuals' digital literacy practices may describe how readers and writers engage in information processing and meaning construction and what individual difference factors come into play in their cognitive engagement (e.g., information-seeking processes using web search engines in Coiro \& Dobler, 2007; strategic processing of multiple sources available on the internet in Afflerbach \& Cho, 2009).

One thing we note here is the possibility that different perspectives could inform, in both distinctive and collective ways, how we examine the multifaceted nature of digital literacies practices. For example, sociolinguistic approaches may help us understand digital forms of discourses within the online space through which youths interact with others who share a common interest in popular culture-for example, video games or fanfiction. Researchers taking these approaches may be highly attentive to noticing and interpreting features of such discourses as social semiotic representations of the youths' emerging identities as experts of the specific popular culture developed through their digital interactions. Further, a closer examination of adolescent writers' motivation demonstrated through their remixing practices in this online space, as well as the capacities and skills employed in such remixing, could help us ponder foundational processes in meaning-making and text construction. While the former approach (i.e., sociolinguistics) helps us explore social phenomena broadly, the latter perspectives (i.e., individual cognition and motivation) certainly assist us in examining a specific individual's cognitive process in digital literacy practices within the social phenomena. Different perspectives substantiate different research foci even on a specific digital literacy practice, but a more integrative methodological approach that interconnects multiple theories and perspectives could help us see things more insightfully. Although different perspectives (and the underlying epistemologies) may never be reconciled completely, a multilayered analysis of the same case could offer useful insights that we might not be able to gain otherwise from a single, limited perspective. Therefore, while we value the distinctive trajectories and boundaries of different perspectives on and inquiries into literacies, we also creatively explore ways of maximizing the benefits of those theories used together.

We found in our review of relevant research literature that there has been a lack of discussion of multidimensional approaches that exploit different theories and perspectives in order to examine the multifaceted practices of digitally literate youth. In this article, we adopt the idea of theoretical triangulation in interpretive inquiry (Denzin, 1978, 2012) and explore how theories that take different perspectives can be intermingled to construct a coherent description of the digital literacies in which young people are engaged. We instantiate a case demonstrating how a multidimensional approach could be generated and used at the intersection of Border-Crossing Discourse (BCD) from a sociocultural perspective, self-determination theory (SDT) from an affective perspective, and the notion of epistemic cognition (EC) from a cognitive perspective. These theories were selected not only because they are rooted in distinctive perspectives on literacies and learning, but also because they offer relatively newly developed frames and tools which are useful for examining digital literacies. We note that our intention is to showcase only one of numerous possibilities of theoretical triangulation toward interpreting digital literacies through a multidimensional approach.

\section{Multidimensional Approaches to Digital Literacies}

\subsection{Diversified Theories of Digital Literacies in the Twenty-First Century}

An important scholarly discourse in recent decades concerns two broad understandings of digital literacies: (a) the forms of literacies afforded by new digital technologies; and (b) literacies as socially situated practices in a digital space (Lankshear \& Knobel, 2006, 2011). For example, Leu, Kinzer, Coiro, Castek and Henry (2013) proposed a dual-level theory of new literacies that accounts for the changing nature of literacy contexts and pedagogical practices for helping students learn the capacities and mindsets involved in digital literacies. One side of this framework includes (lowercase) new literacies that subsume strands of research on the specific area of knowledge, skills, and attitudes newly required in a digitally mediated information space, such as those on the internet. One strand of work under new literacies is focused on online reading comprehension (Castek, 2008; Coiro, 2003; Henry, 2006), with a special interest 
in readers' cognitive strategies to interact with information sources on the internet. The other side of the framework refers to (uppercase) New Literacies, such as new rules for engaging in socially situated digital literacy practices in online social groups, which provides accounts of ideological practices engaged in by young people (e.g., Lankshear \& Knobel, 2014). Similar to Leu et al.'s (2013) dual-level theory, Lankshear and Knobel (2006, 2011) also demonstrate new digital literacies as two kinds of "stuff" - the new technical stuff and the new ethos stuff. The former explains the influence of digital technologies on literacy practices, whereas the latter focuses on the "configuration of values," which involves "different kinds of social and cultural relations" than conventional literacies (Lankshear \& Knobel, 2011, p. 29).

The binary trend of digital literacy research is evident. From sociocultural perspectives, some advocates of New Literacy Studies (NLS) stress socio-spatial approaches to digital literacies and the concept of "space" (Leander, Phillips, \& Taylor, 2010; Mills \& Comber, 2013, 2015; Moje, 2004). Stornaiuolo, Smith and Phillips (2017) develop a framework of "transliteracies" to fit literacy research to today's connected world. Pahl and Escott (2015) emphasize a material-culture approach to literacies to demonstrate the intersection between literacy practices and today's material world by attending to "artifactual literacies" (Pahl \& Rowsell, 2011, 2013). Taking a global perspective, $\operatorname{Kim}(2016 a, 2016 b)$ asserts the importance of "transcultural digital literacies." Lee (2018) reimagines Gee's seminal concept of Discourse with a capital " $D$ " in the contemporary global online world (BCD). In the tradition of psychological cognitive approaches, by contrast, literacy scholars have developed fine-grained theoretical accounts of digital reading. Coiro and Dobler (2007) explore information-seeking processes to demonstrate online reading processes. Cho, Woodward and Li (2017) use the idea of epistemic processing to examine online reading. Furthermore, literacy studies such as McKenna, Conradi, Lawrence, Jang and Meyer (2012) employ affective approaches to examine how adolescents develop their motivation to read print and digital texts in different ways. Some of the same scholars' recent work (Lupo, Jang, \& McKenna, 2017) indicates that adolescents are more motivated to read digital texts for recreational purposes because of the social nature of digital environments.

Concepts of literacies have expanded as tools and environments for reading and writing have taken increasingly complex forms. However, it is impossible to gain a complete understanding of contemporary literacy practices using a theoretical dichotomy. Although theories of digital literacies have become subdivided, specified, and diversified, it is obvious that literacies in reality may not be understood from either psychological (new literacies; technical stuff) or sociocultural (new literacies; ethos stuff) perspectives alone.

We believe that the somewhat divided landscape of research and theories can offer an important opportu- nity for us to see that diversified theoretical developments, in the current digital world, may broaden the possibilities of multidimensional approaches to the study of digital literacies. In this light, the notion of theoretical triangulation offers a useful framework for the exploration of multidimensionality in digital literacies. Triangulation was introduced as a mathematical method for determining the distances and relative positions of points using the laws of trigonometry. Denzin (1970) started using the term in the social sciences to refer to a combination of methodologies in the qualitative study of the same phenomena. Nowadays, it has expanded to include the mixing of qualitative and quantitative methods in multiple phases of research (Denzin, 2012). Denzin described theory triangulation as a way of investigating empirical materials using multiple theories and perspectives that could reveal unnoticed aspects of the data, allowing the construction of more sophisticated accounts of the observed phenomenon, event, or problem (Denzin, 1978). Theoretical triangulation informs our inquiry into literacy practices and processes, as we aim to demonstrate how adolescents' digital literacies can be interpreted differently and coherently by three different perspectives on literacy practices.

In this article, we suggest one possibility for using diversified theories of digital literacies multidimensionally. We use data from our previous work (Lee, 2018) to present an example analysis of youth digital literacies that takes a multidimensional approach. The case in question was previously analyzed on the basis of the theoretical concept of "Border-Crossing Discourse" and by discourse analysis (Gee, 2014). To develop a deeper understanding of the case, we chose two complementary perspectives on literacies and learning: SDT and EC. We first outline these three contemporary theories. We then conduct our case analysis as an example of the possibility of seeing from multidimensional approaches.

We note that our choice of particular theories and perspectives suggests only one possible combination of varied perspectives, as an example of potential multidimensional approaches, anticipating how they could be triangulated into a focused case analysis of youth digital literacies. The specific approach we adopt from each of the three dimensions is based on our review of the recent literature (e.g., Baker, 2010; Coiro et al., 2008; Tracey \& Morrow, 2017). We believe that this attempt may better capture the complexities and nuances of digital literacies practices. In the following section, we discuss each of the three perspectives briefly.

\subsection{Selected Theoretical Views: $B C D, S D T$, and EC}

Our first consideration is a theory informed by NLS that focuses on Gee's work on Discourses with a capital "D" (hereafter, big-D Discourse). In particular, the recently developed concept of $B C D$, grounded in a theory of big-D Discourse, is a powerful tool for examining youth literacies in online societies globally. According to Gee (2015), 
big-D Discourse does not simply mean "discourse" as in language in use or stretches of language longer than a sentence. Rather, it is defined by the ways of behaving, interacting, valuing, thinking, believing, speaking, and often reading and writing that are accepted as instantiations of particular identities by specific social groups (Gee, 2015, p. 7). That is, the literacy practices of a certain social group are situated within a certain Discourse.

The concept of BCD (Lee, 2018; Lee \& Gee, 2018) is a reimagined version of big-D Discourse that has been identified within digitally oriented online social groups across linguistic, social, cultural, and physical boundaries. Lee (2018) called these groups "global online affinity spaces." A global online affinity space is an online space where people who share a specific affinity congregate from all over the world. Inevitably, these spaces become more socially, linguistically, and culturally diverse than other societies. At the same time, strong solidarity based on a shared interest bonds the members of these groups tightly. This solidarity helps diverse people with diverse identities communicate across their social, cultural, and linguistic differences. In literacy studies, the concept of $B C D$ suggests a theoretical viewpoint for exploring digitally situated social languages and literacy practices in global online affinity spaces.

Another consideration is motivational perspectives. We find SDT particularly valuable as a framework for looking at autonomous motivation with relatedness. Beyond the traditional distinction between intrinsic and extrinsic motivation, SDT qualitatively differentiates between types of motivation by situating motivation along a continuum of self-determination or relative autonomy (Ryan \& Deci, 2000). This theoretical differentiation may help us understand why and how individuals in global online affinity spaces participate spontaneously in these social groups in complicated global world.

Deci and Ryan (2008) and Gagné and Deci (2005) explain how SDT distinguishes between autonomous and controlled motivation. Autonomous motivation comprises both intrinsic regulation-engaging in a behavior for one's own satisfaction or enjoyment-and identified regulation-when people have identified with an activity's value and, ideally, have integrated it into their sense of self. Controlled motivation, by contrast, has two subtypes: external regulation, or a sense of pressure from external causes shaping one's actions, and introjected regulation, a sense of having to act from internal pressure. SDT claims that humans exercise these different types of motivation or regulation to fulfill their basic psychological needs for competence, autonomy, and relatedness. Autonomy involves acting with a sense of volition. Competence is the experience of behavior as effectively enacted. Relatedness is feeling connected with contexts in which one experiences a sense of belonging.

Finally, we take the cognition of digital youth into account, as we want to understand how thinking and reasoning are situated within a specific context of literacy practice. We value the recent development of research on the EC of learners, which is known to guide their cognitive processes and behaviors in completing literacy tasks (Hofer, 2004; Kitchner, 1983; Sandoval, Greene, \& Bråten, 2016). In our view, digitally literate youths' reasoning, when processing sources of information, remixing ideas and perspectives, and crafting and sharing their own artifacts, can be explained better by how they respond to and interact with the epistemic value of the internet. The internet presents a textual space for adolescents, who actively sense-make regarding who is authorized to create a text. In a classroom, students' beliefs about and attitudes toward what a text means are constrained by a context in which they have to follow routines and rules set by others, including teachers, textbook authors, and test developers. Consequently, students may believe that what they can do in reading is mostly gathering information to give a correct answer to a given question, and what they can do in writing is producing a limited form of text with a particular structure and content expected by external authorities. Digital spaces, by contrast, may allow adolescents to take ownership of their artifacts as creators. This contextual feature makes reading and writing epistemological tasks in which adolescents, as agentive sense-makers and creative knowledge producers, (un)consciously impose their tacit views of constructive knowledge (knowledge that is constructed in "me") and active knowing (knowing as a process of active meaning-making and representation). Thus, adolescents in a digital space may seek to take the role of active knowers, making claims, consulting multiple sources, constructing evidence, and building arguments about the relevance and value of their artifacts to their target audience. Once these disparate spaces of epistemic values are recognized and experienced, readers and writers can approach their literacy work from newly informed perspectives on what they can do, must do, and must not do in those spaces.

Though these three theoretical ideas attend to different aspects of digital literacy, they are at the same time looking at some common areas. In the following section, we introduce one of our previous studies, in which the data were analyzed using the concept of BCD. Then, we attempt to interpret a sample of the same data through the lenses of SDT and EC. Finally, we discuss the value of multidimensional approaches.

\section{A Case Analysis from Multidimensional Approaches to Digital Literacy Practices}

\subsection{Context: Asianfanfics-Digital Literacies in a Global Online Affinity Space}

The more digital the world becomes, the more diverse and global many of its societies are becoming, and as a result there are many complexified social groups and social practices in the online world. Today's digital world allows social groups to exist in global online affinity spaces (Lee, 2018) where people from all over the world can con- 
gregate on the basis of common interests. Inevitably, this kind of social group includes people of different linguistic, social, cultural, and national backgrounds. The social languages they use are unique and diverse to a degree unprecedented in human history, and their digital literacy practices with these languages are unique types of situated social practices.

Lee (2018) developed the concept of BCD by analyzing multimodal discourse in two such spaces. He used discourse analysis (Gee, 2014) to demonstrate how the social groups created new standards and situated meanings of social languages through the social goods in these spaces. In this article, we use the ideas of SDT and EC to explore this topic further and thus to strengthen the examination of these literacy practices.

The website www.asianfanfics.com (hereafter, Asianfanfics) is devoted to fanfiction about Asian popular culture. We use it as a concrete example from our previous work (Lee, 2018) on the unprecedented but currently typical patterns of digital literacy practices from a global online affinity space. People on Asianfanfics are deeply interested in Asian popular culture broadly; in particular, the majority of them enjoy Korean popular culture (K-pop). This site is a good example of a global online affinity space for two reasons. First, according to Jenkins, Itō, and Boyd (2015), fandom culture and geek culture are not just "sub" cultures anymore. These cultures have become a huge part of our lives, and people within these cultural communities tend to follow new digital media very quickly (Jenkins et al., 2015). Second, people from all around the world congregate on this site due to a shared interest. According to the Flag Counter program, people from at least 151 countries visit Asianfanfics. The site exemplifies current digitalized and globalized social groups very well.

\subsection{Situated Meanings in Asianfanfics}

Lee (2018) explored four kinds of linguistic features in this space. We focus on one of these: "creating new standards and situated meanings of social languages through social goods." To examine this feature, Lee conducted discourse analysis (Gee, 2014), which is useful for exploring linguistic phenomena and situated meanings using data of routine interactions in a specific space. In global online spaces, one of huge barriers to communication is language differences among people in the spaces. However, insiders in a specific social group typically value certain social goods, and they therefore make efforts to overcome the communication barrier through pursuing these social goods. They do so by drawing on various resources (e.g., multimodal and translingual practices), which leads to their spontaneous creation of their own social language and helps them construct and represent their identities as members of that group.

Figures 1 and 2 illustrate a typical use of social languages on Asianfanfics. Figure 1 is a part of the profile page of a young Japanese woman who is introducing the kind of fanfiction and K-pop stars she likes. Figure 2 is a comment on a specific fanfiction on the site.

In the first and second lines of Figure 1, the word "bias" is used several times. This is a common word among English speakers, but its situated meaning in the specific Asianfanfics social space-which is different

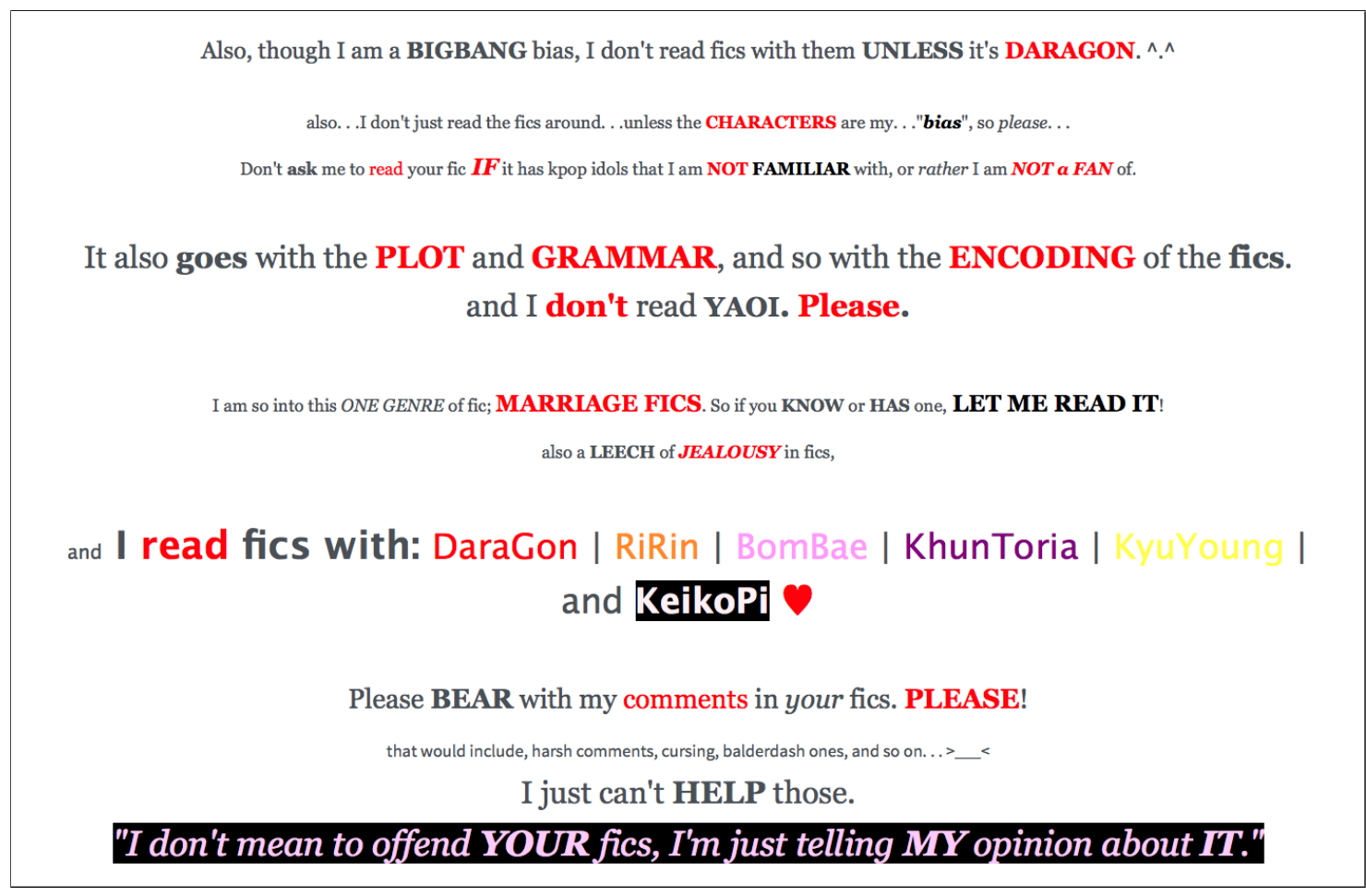

Figure 1. A selected part of a profile page introducing a page owner in Asianfanfics. 
from the meaning in so-called standard English-was created there and is used routinely there. This meaning is currently Urban Dictionary's top definition for the word:

In Kpop, the member of an idol group that is your favorite. A person may have one ultimate bias, and many other biases from other idol groups, or only have one ultimate bias. This term is derived from "having a bias towards a particular person."

G-Dragon is my ultimate bias, but Key is my SHINee bias. (Urban Dictionary, n.d.)

The author uses other common words on Asianfanfics, such as "DaraGon," "RiRin," "BomBae," "KhunToria," "KyuYoung," and "KeikoPi." These are typical examples of words that insiders to Asianfanfics employ to depict K-pop stars. There are detailed processes for representing identities through these social languages and many more examples (see Lee, 2018, pp. 84-86).

Figure 2 shows a reader's comment on a work of fanfiction on Asianfanfics. Outwardly, it appears to be a paragraph of typical English. But on a closer look, it combines at least two languages. For example, in the first line, the words "sasaeng" (사생) and "Yoona" (윤아) are Korean. The last sentence uses a hybrid expression with a specific situated meaning: the Korean suffix “-nim" (님) means honorable or respectable. People in Korea routinely use it to address people in honorable positions, such as teachers, professors, judges, and religious leaders. However, no one calls a writer "author-nim," even in Korea, except Koreans who participate in Asianfanfics (there is another way to refer to an author using "-nim" in Korean). As Lee said, "In Asianfanfics, users don't refer to an author as just an author but rather as 'author-nim.' This is a kind of tacit rule and one of their social goods that everyone tries to follow" (Lee, 2018, p. 86).

\section{5 \#11 Feb 11, 20169:38:20 Reply All}

And btw, that $B$ sasaeng fans is also stalking Yoona, a past SM Rookies trainee, and SM rookies? I don't know how I supposed to react since I want to auditioned for SM... In the Entertainment Weekly, there's this female student calling out to Chen (but got cut out) when she asked if Chen used to date Apink member before, huh, I wonder if she's one of the sasaeng. But I support my bae with anyone as long as he's happy! I just don't ship and pairing OTP. This blog is really helpful. Thank you author-nim!

Figure 2. A reader's comment on a popular fanfiction about K-pop stars.

Endeavors to pursue social goods within certain social groups lead to people continually creating and using the social languages in the group. Participants want to be seen as insiders, and to do so they use the social lan- guages "spontaneously." In particular, in global online affinity spaces where culturally, linguistically, and nationally diverse people congregate, social languages develop in very dynamic and complex ways (Lee, 2018). The members also obviously acquire these social language proficiencies not from teachers and school curricula (Lankshear \& Knobel, 2014), but as active participants. In the following sections, we use SDT and EC to explore the cognitive side of how they do these activities.

\subsection{Why and How Do People Determine to Keep Using and Creating New Situated Meanings and Social Languages?}

Within the Asianfanfics community, users from different countries feel connected to each other; they develop a sense of belonging by caring and being cared for (Gee, 2004; Lee, 2018). This sense of relatedness promotes the process of internalizing social languages and discourses as their own values. For example, in Figure 1, the girl who introduced herself as Japanese autonomously tries to use Korean, Korean-relevant, and K-pop-related language with English grammatical structures rather than Japanese on her profile page to connect with other participants. And while the autonomous motivation that many users have when they start participating in the global online affinity space may be personal and intrinsic, it may develop into more community-oriented identified regulation as they internalize the discourses shared in the community as their own practices.

In addition, as seen in Figure 2, these users are autonomous (autonomy) because they are willing to devote their time and energy to using, creating, and sharing social languages by posting new information and responding to other postings. They are competent as well (competence) because they challenge each other with their thoughts about their favorite K-pop stars and share constructive feedback with each other regarding the quality of the information they have shared (relatedness). In this regard, the Asianfanfics site clearly addresses all the three basic psychological needs (competence, autonomy, and relatedness, Deci \& Ryan, 2008), which in turn promotes the users' autonomous engagement in using and sharing social languages.

\subsection{How Do Epistemic Beliefs in the Popular Culture Shape the Engagement Experience of the Social Languages?}

One's epistemic beliefs may not be presented explicitly to others. These beliefs rather operate implicitly as tacit knowledge but come to the surface when the knower is prompted by a self-initiated goal and need. Epistemic beliefs become realized in action within authentic contexts of meaning-making, in which knowers recognize the autonomy of their work. From this perspective, the notions of grammar, English language, and text could be reconceived. Young people's beliefs about knowledge 
(what counts as knowledge) and knowing (how one comes to know) would be distinct from what they believe and bring to their work in constrained school literacy contexts.

School grammars are fixed and cannot be changed or modified by users. They offer a sort of discrete knowledge that students must memorize and be able to access and retrieve when reading and writing. What they read and write is also represented as a form of text, one written in standard language by expert readers and writers. In this context, there is little room for students to imagine their roles as text participants or analysts who can critically challenge text and language, and who can creatively mix varied language forms and grammars into a text adhering to student-created rules.

Many contrasting enactments of epistemic beliefs can be observed and interpreted in the Asianfanfics online affinity space. K-pop is rooted in Korean popular music and its commodified culture, but the real meaning of $\mathrm{K}$-pop is redefined by those who engage in listening to it together, sharing reviews, and building a community in which multiple cultures and language tools are used. The languages, symbols, and meanings are reauthorized by the sign-makers, and the processes of managing such tools and resources are meticulously reviewed and examined by other members of the community (see Figure 2). In this space, young readers and writers become authorities and experts who are equipped with highly valued knowledge and skills, and who constantly monitor their processes of tool-using and meaning-making. This open, constructive epistemic community has rules and standards for making judgments on their languages and tool uses, which then drive the choice of tools and languages, the exploration of new tools and new modifications of language, and the creation of multiple opportunities to test such meaning-making tools and processes. Therefore, cognitive strategies and metacognitive controls are situated in the way readers and writers respond to their constructively negotiated grammars, languages, texts, as well as to the authorities of all intellectual products.

\section{What We Learn from the Case Analysis on Youth Digital Literacies}

Guided by the theoretical triangulation framework (Denzin, 1978, 2012), we have attempted in this study to interpret a digital literacies practice through three different lenses and show the advantages of multidimensional approaches. The use of three approachesBCDs from the sociocultural dimension, SDT from the affective dimension, and EC theory from the cognitive dimension-strengthened and corroborated each of the perspectives' interpretations. The analysis exploring the situated meanings of discourse in the Asianfanfics community from the BCD perspective allowed us to identify unique structures, norms, and rules of the site's social languages. The participants have created new situated meanings of existing words (e.g., "bias") and developed new tactics for forming new words (e.g., combining the final syllables of two K-pop stars' names to indicate a pairing within a fanfic: Sandara + G-dragon = daragon).

The notion of autonomous motivation proposed by SDT is a useful conceptual framework for capturing the multifaceted nature of users' motivations: it explains why the site's users spontaneously participate in the society and continuously create their own social languages (as addressed from the BCD perspective). Readers and writers of fanfictions in the space have strong autonomous motivations (i.e., intrinsic and identified regulations) for writing the fanfics and responding to them in their own social languages. Their affinity for certain $\mathrm{K}$-pop stars and the desires and fantasies they want to realize may provide the strong intrinsic regulation behind their writing. At the same time, they gain benefits by using the social languages in order to be understood by other users and mark themselves as "insiders" to other K-pop fans (Black, 2008). SDT explains this tendencywanting to actualize a social good, in this case to be marked as an insider-through the concept of "relatedness," which is used from the motivational perspective. That is, the writers' autonomous motivation for strengthening their relatedness to others in the space fosters their using and creating the new situated meanings of the social languages of the spaces.

In addition, examining the beliefs and cognitive processes of users of Asianfanfics about their own knowledge and knowing in their online reading and writing helps us explain why and how they stick to certain social languages, contents, and/or writing formats in their fanfics. According to big-D Discourse theory, active participation in a particular affinity space lets young people acquire social language proficiencies aptly without formal education (Lankshear \& Knobel, 2014). Advocates of big-D Discourse theory sometimes attempt to explain this phenomenon-the acquisition of social language proficiency by participation-through the term "figured world," which describes a space of shared values, beliefs, or faiths within a certain Discourse or "cultural model." While the BCD tries to uncover how such proficiency is acquired in terms of the characteristics of online spaces broadly, an analysis focused on EC tries to identify how a certain individual in an affinity space can, specifically and cognitively, develop social language proficiency based on each individual's epistemic beliefs in regard to the space, its contents, or the characteristics of the social group. Understanding such individual beliefs could be beneficial to develop concrete pedagogical approaches.

Figure 3 visualizes the interconnectedness of the three approaches. We compare our examination of a digital literacies practice through three different theoretical dimensions to the use of three overlapping colored lenses to observe an object. For example, when the yellow lens overlaps the blue one, the common area turns to green, and allows us to identify a new "green" object. The lenses do not change the object. Instead, they help us view the same object differently. 


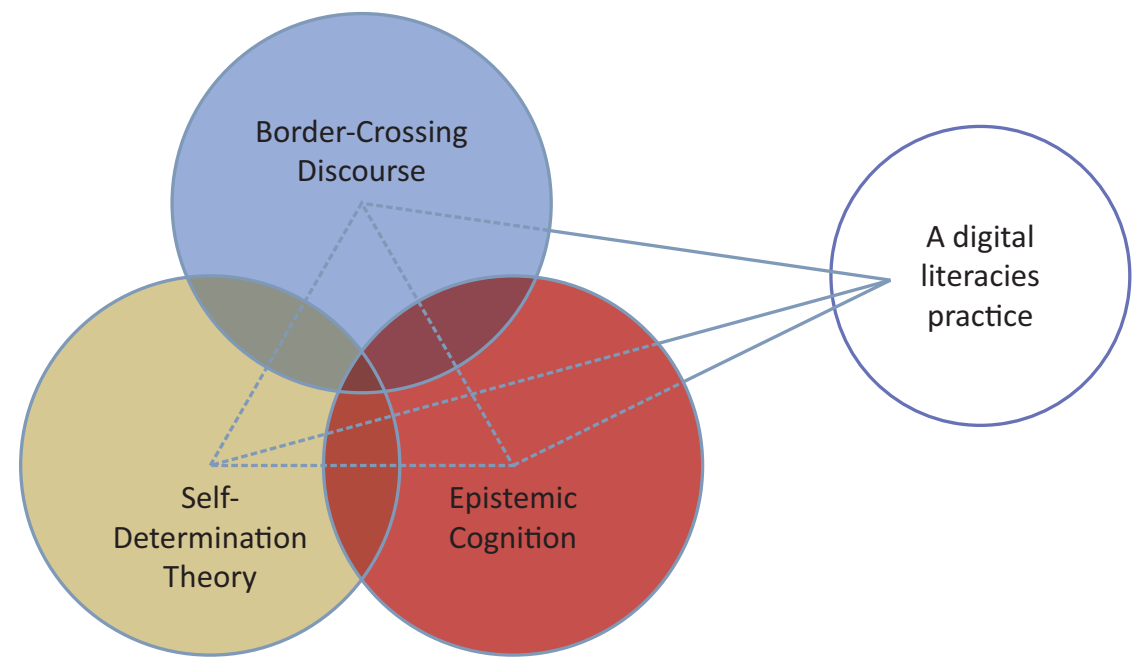

Figure 3. Interconnectedness of the three approaches.

Likewise, our three approaches help us interpret a certain digital literacies practice in a manner different from what any one approach could lead to on its own. By applying SDT and EC together, for example, we can understand the interplay between the users' epistemic beliefs and their autonomous motivation. According to Chen and Barger's (2016) review of the relationship between epistemic beliefs and motivation, people's beliefs about their knowledge and knowing drive their motivation for learning. That is, the common area between SDT and EC helps us explicate that the Asianfanfics users' belief in their authority and expertise about knowledge and knowing in the online space motivates them to belong to the community with "autonomy" and "competence" (Deci \& Ryan, 2008).

Second, the shared area between SDT and BCD allows us to interpret the relationship between users' autonomous motivation and situated meanings in online affinity spaces. Although no established theory specifically addresses this relationship, a few existing studies report that participation in an affinity space is "multifaceted," including the self-directed autonomous pursuit of "relatedness" to other users (e.g., Curwood, Magnifico, \& Lammers, 2013). This tendency results in the users' desire to actualize their unique "social goods," which were identified by BCD (Lee, 2018, p. 86).

In addition, the overlap between BCD and EC explains the desire to pursue the social goods in relation to the users' knowledge about the website and texts as the space and medium of their epistemic beliefs. In other words, since the users perceive the global online affinity space as involving out-of-school literacies, and they believe that they belong to a space where young readers and writers have ownership and authority of the content (Cho et al., 2017), they are willing to develop their own rules to perpetuate their figured worlds (Lee, 2018). UItimately, combining the three different perspectives enables us to speculate about the digital literacies practice more deeply and eclectically.

\section{Concluding Remarks}

This study suggested a promising possibility for understanding multiple aspects of digital literacy practices in a global online affinity space by using three perspectives to interpret an example of discourse from the Asianfanfics website. For example, we showed how social languages are created and become privileged in a specific digital world; how autonomous motivation and relatedness drive young people to acclimate to the social language use; and how an individual's beliefs and cognitive processes regarding his or her personal knowledge and knowing affect the development of social language proficiency in a global online affinity space. In the article's multidimensional analysis through the lenses of three recently developed theoretical views, each perspective complements the others to provide explanations that transcend single viewpoints.

However, this study has several limitations. First, users' motivations and epistemic beliefs were assumed solely on the basis of the written discourses on the website. To more fully exploit this theoretical triangulation framework as a powerful analytical tool, future studies could employ interview and think-aloud methods to collect data. Doing so would provide understanding about the affective and cognitive aspects of users' digital literacy practices. Second, this study selected three specific approaches from three dimensions in which the authors specialize. We expect that different combinations of theoretical approaches-such as socio-spatial approaches, multimodal social semiotics, artifactual literacies, translanguaging, and cognitive-process theories of writing - may also be meaningful lenses for interpreting digital literacy practices. Finally, such eclectic theorizing is relatively new in the field of digital literacies. We examined only a brief case from a specific online affinity space. Therefore, we are not yet at the stage of naming the overlapping areas and defining directions among the perspectives. However, we believe that future stud- 
ies that triangulate different perspectives will eventually generate new theories with new names and help us achieve a more sophisticated understanding of digital literacy practices.

\section{Acknowledgments}

We thank anonymous reviewers for their careful reading of our manuscript and their many thoughtful comments and suggestions.

\section{Conflict of Interests}

The authors declare no conflict of interests.

\section{References}

Afflerbach, P., \& Cho, B.-Y. (2009). Identifying and describing constructively responsive comprehension strategies in new and traditional forms of reading. In S. E. Israel \& G. G. Duffy (Eds.), Handbook of research on reading comprehension (pp. 69-90). New York, NY: Routledge.

Alvermann, D. E. (Ed.). (2010). Adolescents' online literacies: Connecting classrooms, digital media, and popular culture. New York, NY: Peter Lang.

Anderson, R. C., \& Pearson, P. D. (1984). A schematheoretic view of basic processes in reading comprehension. In P. D. Pearson (Ed.), Handbook of reading research (1st ed., pp. 255-291). New York, NY: Routledge.

Baker, E. A. (2010). The new literacies: Multiple perspectives on research and practice. New York, NY: The Guilford Press.

Black, R. W. (2008). Adolescents and online fan fiction. New York, NY: Peter Lang.

Castek, J. (2008). How do 4th and 5th grade students acquire the new literacies of online reading comprehension? Exploring the contexts that facilitate learning (Unpublished doctoral dissertation). University of Connecticut, Storrs.

Chen, J. A., \& Barger, M. M. (2016). Epistemic cognition and motivation. In J. A. Greene, W. A. Sandoval, \& I. Bråten (Eds.), Handbook of epistemic cognition (pp. 425-438). New York, NY: Routledge.

Cho, B.-Y., Woodward, L., \& Li, D. (2017). Epistemic processing when adolescents read online: A verbal protocol analysis of more and less successful online readers. Reading Research Quarterly, 53(2), 197-221. https://doi.org/10.1002/rrq.190

Coiro, J. (2003). Reading comprehension on the Internet: Expanding our understanding of reading comprehension to encompass new literacies. The Reading Teacher, 56(5), 458-464.

Coiro, J., \& Dobler, E. (2007). Exploring the online reading comprehension strategies used by sixth-grade skilled readers to search for and locate information on the Internet. Reading Research Quarterly, 42(2),
214-257. https://doi.org/10.1598/RRQ.42.2.2

Coiro, J., Knobel, M., Lankshear, C., \& Leu, D. J. (2008). Handbook of research on new literacies. New York, NY: Routledge.

Curwood, J. S., Magnifico, A. M., \& Lammers, J. C. (2013). Writing in the wild: Writers' motivation in fan-based affinity spaces. Journal of Adolescent \& Adult Literacy, 56(8), 677-685.

Deci, E. L., \& Ryan, R. M. (2008). Self-determination theory: A macrotheory of human motivation, development, and health. Canadian Psychology/Psychologie Canadienne, 49(3), 182-185. https://doi.org/ $10.1037 / a 0012801$

Denzin, N. K. (1970). The research act: $A$ theoretical introduction to sociological methods (1st ed.). Chicago, IL: Aldine.

Denzin, N. K. (1978). The research act: A theoretical introduction to sociological methods (2nd ed.). New York, NY: McGraw-Hill.

Denzin, N. K. (2012). Triangulation 2.0. Journal of MixedMethod Research, 6(2), 80-88.

Flower, L., \& Hayes, J. R. (1981). A cognitive process theory of writing. College Composition and Communication, 32(4), 365-387. https://doi.org/10.2307/ 356600

Gagné, M., \& Deci, E. L. (2005). Self-determination theory and work motivation. Journal of Organizational Behavior, 26(4), 331-362. https://doi.org/10.1002/ job.322

Gee, J. P. (1990). Social linguistics and literacies: Ideology in discourses. New York, NY: Routledge.

Gee, J. P. (2004). Situated language and learning: A critique of traditional schooling. New York, NY: Routledge.

Gee, J. P. (2014). An introduction to discourse analysis: Theory and method. New York, NY: Routledge.

Gee, J. P. (2015). Social linguistics and literacies: Ideology in discourses (5th ed.). New York, NY: Routledge.

Gee, J. P., \& Hayes, E. (2010). Women and gaming: The Sims and 21st century learning. New York, NY: Palgrave Macmillan.

Henry, L. A. (2006). SEARCHing for an answer: The critical role of new literacies while reading on the internet. The Reading Teacher, 59(7), 614-627. https:// doi.org/10.1598/RT.59.7.1

Hofer, B. K. (2004). Epistemological understanding as a metacognitive process: Thinking aloud during online searching. Educational Psychologist, 39(1), 43-55. https://doi.org/10.1207/s15326985ep3901_5

Hull, G. A., Stornaiuolo, A., \& Sahni, U. (2010). Cultural citizenship and cosmopolitan practice: Global youth communicate online. English Education, 42(4), 331-367.

Hull, G. A., Stornaiuolo, A., \& Sterponi, L. (2013). Imagined readers and hospitable texts: Global youths connect online. In D. E. Alvermann, N. J. Unrau, \& R. B. Ruddell (Eds.), Theoretical models and processes of reading (6th ed., pp. 1208-1240). Newark, DE: Inter- 
national Reading Association.

Jenkins, H., Itō, M., \& Boyd, D. (2015). Participatory culture in a networked era: A conversation on youth, learning, commerce, and politics. Cambridge and Malden, MA: Polity Press.

Jiménez, R. T. (2000). Literacy and the identity development of Latina/o students. American Educational Research Journal, 37(4), 971-1000. https://doi.org/ 10.3102/00028312037004971

Jiménez, R. T., Smith, P. H., \& Teague, B. L. (2009). Transnational and community literacies for teachers. Journal of Adolescent \& Adult Literacy, 53(1), 16-26. https://doi.org/10.1598/JAAL53.1.2

Kim, G. M. (2016a). Practicing multilingual identities: Online interactions in a Korean dramas forum. International Multilingual Research Journal, 10(4), 254-272. https://doi.org/10.1080/19313152.2016.1192849

Kim, G. M. (2016b). Transcultural digital literacies: Crossborder connections and self-representations in an online forum. Reading Research Quarterly, 51(2), 199-219. https://doi.org/10.1002/rrq.131

Kintsch, W. (1988). The role of knowledge in discourse comprehension: A construction-integration model. Psychological Review, 95(2), 163-182. https://doi. org/10.1037/0033-295X.95.2.163

Kitchner, K. S. (1983). Cognition, metacognition, and epistemic cognition. Human Development, 26(4), 222-232. https://doi.org/10.1159/000272885

Lam, W. S. E., \& Rosario-Ramos, E. (2009). Multilingual literacies in transnational digitally mediated contexts: an exploratory study of immigrant teens in the United States. Language and Education, 23(2), 171-190. https://doi.org/10.1080/09500 780802152929

Lankshear, C., \& Knobel, M. (2006). New literacies: Everyday practices and classroom learning (2nd ed.). New York, NY: Open University Press.

Lankshear, C., \& Knobel, M. (2011). New literacies: Everyday practices and classroom learning (3rd ed.). New York, NY: Open University Press.

Lankshear, C., \& Knobel, M. (2014). Englishes and digital literacy practices. In C. Leung \& B. V. Street (Eds.), The routledge companion to English language studies (pp. 451-463). New York, NY: Routledge.

Leander, K. M., Phillips, N. C., \& Taylor, K. H. (2010). The changing social spaces of learning: Mapping new mobilities. Review of Research in Education, 34(1), 329-394. https://doi.org/10.3102/0091732X 09358129

Lee, K. M. (2018). New approaches to literacies studies in the digital and globalizing world: Border-Crossing Discourses in the global online affinity spaces (Unpublished doctoral dissertation). Arizona State University, Tempe.

Lee, K. M., \& Gee, J. P. (2018). Global communication within re-imagined big " $D$ " Discourses across boundaries: Discourses in international online affinity spaces. Paper presented at the American Educa- tional Research Association, New York, NY.

Leu, D. J., Kinzer, C. K., Coiro, J., Castek, J., \& Henry, L. A. (2013). New literacies: A dual level theory of the changing nature of literacy, instruction, and assessment. In D. E. Alvermann, N. J. Unrau, \& R. B. Ruddell (Eds.), Theoretical models and processes of reading (6th ed., pp. 1150-1181). Newark, DE: International Reading Association.

Lupo, S., Jang, B. G., \& McKenna, M. (2017). The relationship between reading achievement and attitudes toward print and digital texts in adolescent readers. Literacy Research: Theory, Method, and Practice, 66(1), 264-278. https://doi.org/10.1177/23813369 17719254

McKenna, M. C., Conradi, K., Lawrence, C., Jang, B. G., \& Meyer, J. P. (2012). Reading attitudes of middle school students: Results of a U.S. Survey. Reading Research Quarterly, 47(3), 283-306. https://doi.org/ 10.1002/rrq.021

Mills, K. A., \& Comber, B. (2013). Space, place and power: The spatial turn in literacy research. In K. Hall, T. Cremin, B. Comber, \& L. C. Moll (Eds.), International handbook of research on children's literacy, learning, and culture (pp. 412-423). Somerset, NJ: John Wiler \&. Sons.

Mills, K. A., \& Comber, B. (2015). Socio-spatial approaches to literacy studies: Rethinking the social constitution and politics of space. In J. Rowsell \& K. Pahl (Eds.), The routledge handbook of literacy studies (pp. 91-103). New York, NY: Routledge.

Moje, E. B. (2004). Powerful spaces: Tracing the out-ofschool literacy spaces of Latino/a youth. In K. M. Leander \& M. Sheehy (Eds.), Spatializing literacy research and practice (pp. 15-38). New York: NY: Peter Lang.

Moje, E. B., \& Lewis, C. (2007). Examining opportunities to learn literacy: The role of critical sociocultural literacy research: Reframing sociocultural research on literacy. In C. Lewis, P. Enciso, \& E. B. Moje (Eds.), Identity, agency, and power: Reframing sociocultural research on literacy (pp. 15-48). New York, NY: Routledge.

Moll, L. C., Amanti, C., Neff, D., \& Gonzalez, N. (1992). Funds of knowledge for teaching: Using a qualitative approach to connect homes and classrooms. Theory into Practice, 31(2), 132-141.

Morrell, E. (2004). Becoming critical researchers: Literacy and empowerment for urban youth. Bern: Peter Lang. Retrieved from https://www.peterlang.com/ view/title/57936

Pahl, K., \& Escott, H. (2015). Materialising literacies. In J. Rowsell \& K. Pahl (Eds.), The Routledge handbook of literacy studies (pp. 489-503). New York, NY: Routledge.

Pahl, K., \& Rowsell, J. (2011). Artifactual critical literacy: A new perspective for literacy education. Berkeley Review of Education, 2(2), 129-151.

Pahl, K., \& Rowsell, J. (2013). Artifactual literacies. In J. 
Larson \& J. Marsh (Eds.), The SAGE handbook of early childhood literacy (2nd ed., pp. 263-278). London: Sage.

Ryan, R. M., \& Deci, E. L. (2000). Self-determination theory and the facilitation of intrinsic motivation, social development, and well-being. American Psychologist, 55(1), 68-78. https://doi.org/10.1037/0003066X.55.1.68

Sandoval, W. A., Greene, J. A., \& Bråten, I. (2016). Understanding and promoting thinking about knowledge: Origins, issues, and future directions of research on epistemic cognition. Review of Research in Education, 40(1), 457-496. https://doi.org/10.3102/ $0091732 \times 16669319$

Skerrett, A. (2015). Teaching transnational youth: Liter- acy and education in a changing world. New York, NY: Teachers College Press.

Stornaiuolo, A., Smith, A., \& Phillips, N. C. (2017). Developing a transliteracies framework for a connected world. Journal of Literacy Research, 49(1), 68-91. https://doi.org/10.1177/1086296X16683419

Street, B. V. (1995). Social literacies: Critical approaches to literacy in development, ethnography and education. New York, NY: Longman.

Tracey, D. H., \& Morrow, L. M. (2017). Lenses on reading: An introduction to theories and models (3rd ed.). New York, NY: The Guilford Press.

Urban Dictionary. (n.d.). Bias. Urban Dictionary. Retrieved from https://www.urbandictionary.com/ define.php?term=bias

\section{About the Authors}

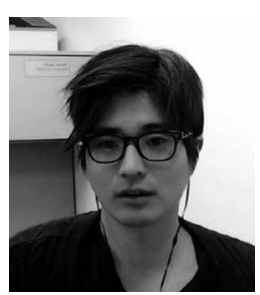

Kewman M. Lee is an Assistant Professor in the Department of Reading, Foundations and Technology at Missouri State University. His research focuses on digital literacies in transnational online spaces, Border-Crossing Discourse, literacies and learning in out-of-school contexts, pop culture and literacies, the new literacies studies, multimodality, and discourse analysis. He teaches various literacies courses for undergraduate and graduate students.
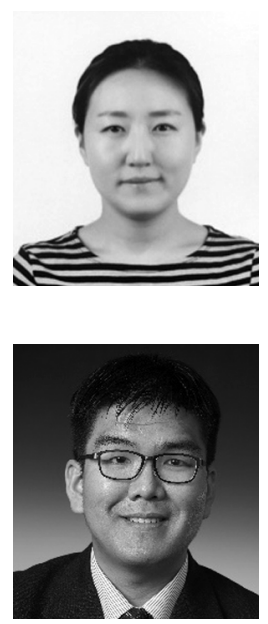

Bong Gee Jang is an Assistant Professor in the Department of Reading and Language Arts at Syracuse University. His main areas of research include literacy motivation, engagement in digital settings, and disciplinary/content literacy. His research has appeared in such journals as Reading Research Quarterly, Educational Psychology Review, Literacy Research: Theory, Method, and Practice, Journal of Adolescent \& Adult Literacy, and The Reading Teacher. Bong Gee teaches courses related to disciplinary literacy and language arts for both pre-service and in-service teachers. He also teaches introductory and advanced research methods courses to graduate students.

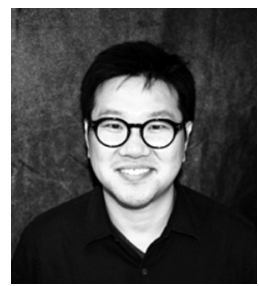

Byeong-Young Cho is Associate Professor of Language, Literacy, and Culture at the University of Pittsburgh School of Education and Research Scientist at Pitt's Learning Research and Development Center. Cho's research focuses on new literacies and classroom practices to support student learning in the digital age. His work has appeared in leading journals such as American Educational Research Journal, Reading Research Quarterly, and Cognition and Instruction, to name a few. 